\title{
CHANGES ON DATA COLLECTION SCALE INFLUENCING THE BIDIRECTIONAL REFLECTANCE DISTRIBUTION FUNCTION
}

\author{
Jefferson Fernandes Teixeira Junior ${ }^{1,2}$, Ruy Morgado de Castro ${ }^{1,3}$ and Flavio Jorge Ponzoni ${ }^{2}$
}

\begin{abstract}
Comparing remote sensing data acquired at different data acquisition geometries is commonly carried out considering the angular dependencies of the electromagnetic radiation reflection described by the bidirectional reflectance distribution function (BRDF). Thus, this function is assumed to be invariant for any acquisition level (laboratory, field, airborne and orbital), which here will be treated as "scale". We characterized the BRDF of three surfaces with different superficial characteristics, using $1^{\circ}, 8^{\circ}$ and $25^{\circ}$ field of view (FOV) optics to simulate different acquisition levels to investigate feasible influences on radiometric quantities by changing scales. Measurements of reflectance quantities were performed using a goniometer developed by the Laboratório de Radiometria e Caracterização de Sensores Eletro-ópticos (LaRaC) of the Instituto de Estudos Avançados (IEAV). The results showed that depending on surface characteristics, different BRDF behaviors can be observed according to the viewing optics. In general, surface BRDFs obtained by $8^{\circ}$ and $25^{\circ}$ FOVs showed very similar behaviors and values. On the other hand, surface BRDFs obtained by $1^{\circ}$ FOV were comparable to the obtained with others FOVs only in the case of a flat surface.
\end{abstract}

Keywords: surface, reflectance, anisotropy.

RESUMO. A comparação de dados de sensoriamento remoto adquiridos em diferentes geometrias de aquisição de dados é geralmente realizada considerando as dependências angulares da reflexão da radiação eletromagnética, descrita pela função de distribuição de reflectância bidirecional (BRDF). Assim, esta função é assumida como invariante para qualquer nível de aquisição (laboratório, campo, aerotransportado e orbital), que aqui será tratado com o termo "escala". Neste trabalho, realizamos a caracterização da BRDF de três superfícies com diferentes características superficiais, utilizando ópticas de $1^{\circ}, 8^{\circ}$ e $25^{\circ}$ de campo de visada (FOV) para simular diferentes níveis de aquisição, com o objetivo de investigar possíveis influências em grandezas radiométricas devido à mudança de escalas. As medições das grandezas de reflectância foram realizadas utilizando um goniômetro desenvolvido pelo Laboratório de Radiometria e de Caracterização de Sensores Eletro-ópticos do Instituto de Estudos Avançados (LaRaC/IEAV). Os resultados mostraram que, dependendo das características da superfície, diferentes comportamentos de BRDF podem ser observados de acordo com as ópticas do sensor. Em geral, as BRDFs obtidas com FOVs de $8^{\circ}$ e $25^{\circ}$ apresentaram comportamentos e valores muito semelhantes. Por outro lado, as BRDFs obtidas com FOV de $1^{\circ}$ foram análogas àquelas obtidas com outros FOVs apenas no caso de uma superfície plana e uniforme.

Palavras-chave: superfície, reflectância, anisotropia.

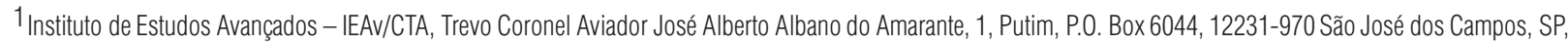
Brazil. Phone: +55(12) 3947-5360 - E-mails: jefferson.junior@hotmail.com; rmcastro@ieav.cta.br

2 Instituto Nacional de Pesquisas Espaciais - INPE, Divisão de Sensoriamento Remoto, Av. dos Astronautas, 1758, Jardim da Granja, P.0. Box 12227-010 São José dos Campos, SP, Brazil. Phone: +55(12) 3208-6454 - E-mail: flavio@dsr.inpe.br

3 Universidade de Taubaté - UNITAU, Departamento de Matemática e Física, Avenida Marechal Deodoro, 605, Santa Clara, P.0. Box 515, 12201-970, 12080-000 Taubaté, SP, Brazil. Phone: +55(12) 3629-5982 - E-mail: rmcastro@unitau.br
} 


\section{INTRODUCTION}

Remote sensing data have been acquired from different levels (laboratory, field, airborne and orbital) and geometries (illumination and observing) and frequently researchers or professionals in general need to compare themselves. However, such comparison is not trivial and sometimes some assumptions are not strictly considered.

During field campaigns dedicated to the absolute calibration of orbital sensors ("vicarious" calibration), for example, a reference surface, which presents specific spectral characteristics, is arbitrarily selected and radiometric measurements are performed on it during the orbital sensor overpass. These radiometric measurements frequently result on radiance or reflectance values that are directly related to the radiometric data collected by the orbital sensor. When off-nadir viewing is considered, goniometers have been utilized to characterize the Bidirectional Reflectance Distribution Function (BRDF) of the reference surface and it has been assumed that the same BRDF should be obtained from the orbital data. So, again the field data and the orbital ones have been directly related.

Intuitively speaking we could review the four domains involved on the remote sensing technology trying to fully understand all aspects involved on such relationship: spatial, spectral, radiometric and temporal domains. Concerning the spatial domain, it is obvious that during the radiometric data collection on the reference surface just numerous small portions (generally around $0.04 \mathrm{~m}^{2}$ for laboratory measurements with sensor-surface distance of $0.5 \mathrm{~m}$ ) of the reference surface are spectrally characterized while the orbital sensor collects data from relatively larger areas (frequently larger than $400 \mathrm{~m}^{2}$ ). It should not be a problem since the surface is considered homogenous, but it does not. Think on the micro relief of the reference surface. It can significantly influence the surface reflectance (and the BRDF as well) in absolute terms measured from a portable radiometer in the field, but similar influence cannot be significant at orbital data collection level.

Concerning both spectral and radiometric domains the field data can reveal spectral variances between successive measurements that also cannot be "felt" by the orbital sensor and, of course, the two sensors involved (field and orbital) have different signal/noise ratios.

Finally, considering the temporal domain, we must consider that the field and orbital data are not acquired at the same time. Commonly the field data are collected during a time interval in which the satellite overpass is included. This time interval is frequently of one hour (Pinto, 2011) while the orbital sensor collects data from the reference surface during few seconds.
Goodchild \& Quattrochi (1997) mentioned such aspects as "scale" resultants. Here "scale" is treated most as data acquisition level than its classical cartographic definition. Actually, trying to simplify a complex interaction process, we assume that the reference reflectance (or its BRDF) propagates from the field level until the orbital one as no different equipment, timing, spectral, radiometric and spatial aspects were involved.

Surface roughness and texture influence the preferential shadowing direction besides determining the reflection direction (Mather \& Koch, 2011), but the relative observer (or sensor) positioning can influence the effective radiance measured as the spectral characteristics of the surface changed. Gamon et al. (2006) presented a good illustration of this phenomenon that can be observed on Figure 1.

Figure 1 provides a good opportunity to fully understand that, at each data acquisition level, the same surface or object may vary its appearance according the height and, thus, they may present different spectral characterization (particular at each level), including in angular terms (BRDF).

The objective of our study is to evaluate the influence of the scale on the BRDF of different surfaces.

\section{MATERIAL AND METHODS}

An in-lab experiment was conducted at the LaRaC (Laboratório de Radiometria e Caracterização de Sensores Eletro-ópticos) of the Advanced Studies Institute (IEAv) in São José dos Campos, SP, Brazil (Castro et al., 2017).

The experiment was based on simulating three different data acquisition scales using a goniometer in which an ASD FieldSpec spectroradiometer, running from 350 to $2500 \mathrm{~nm}$, was attached. As it would be impossible changing the distance between the sensor and the observed surface, the scales were simulated changing the FOVs using three optics $\left(1^{\circ}, 8^{\circ}\right.$ and $\left.25^{\circ}\right)$. Such simulations were carried out in three different surfaces made by plaster (diameter around $30 \mathrm{~cm}$ and $2 \mathrm{~cm}$ of thickness) being one (S1) totally flat and silky, another one (S2) with nearly parallel grooves $(1.5 \mathrm{~cm}$ spacing and $1.0 \mathrm{~cm}$ depth) and the third surface (S3) presenting random grooves (no more than $2.0 \mathrm{~cm}$ thick and $1.0 \mathrm{~cm}$ deep), as shown in Figure 2.

Such strategy was based on Mather \& Koch (2011) that explored roughness and texture of objects observed at different scales. Figure 3 shows the goniometer utilized.

The LaRaC Goniometer project was mainly based on CLabSpeG (Compact Laboratory Spectro-Goniometer) from University of Leuven (Biliouris et al., 2007), regarding to its dimensions and structures. 


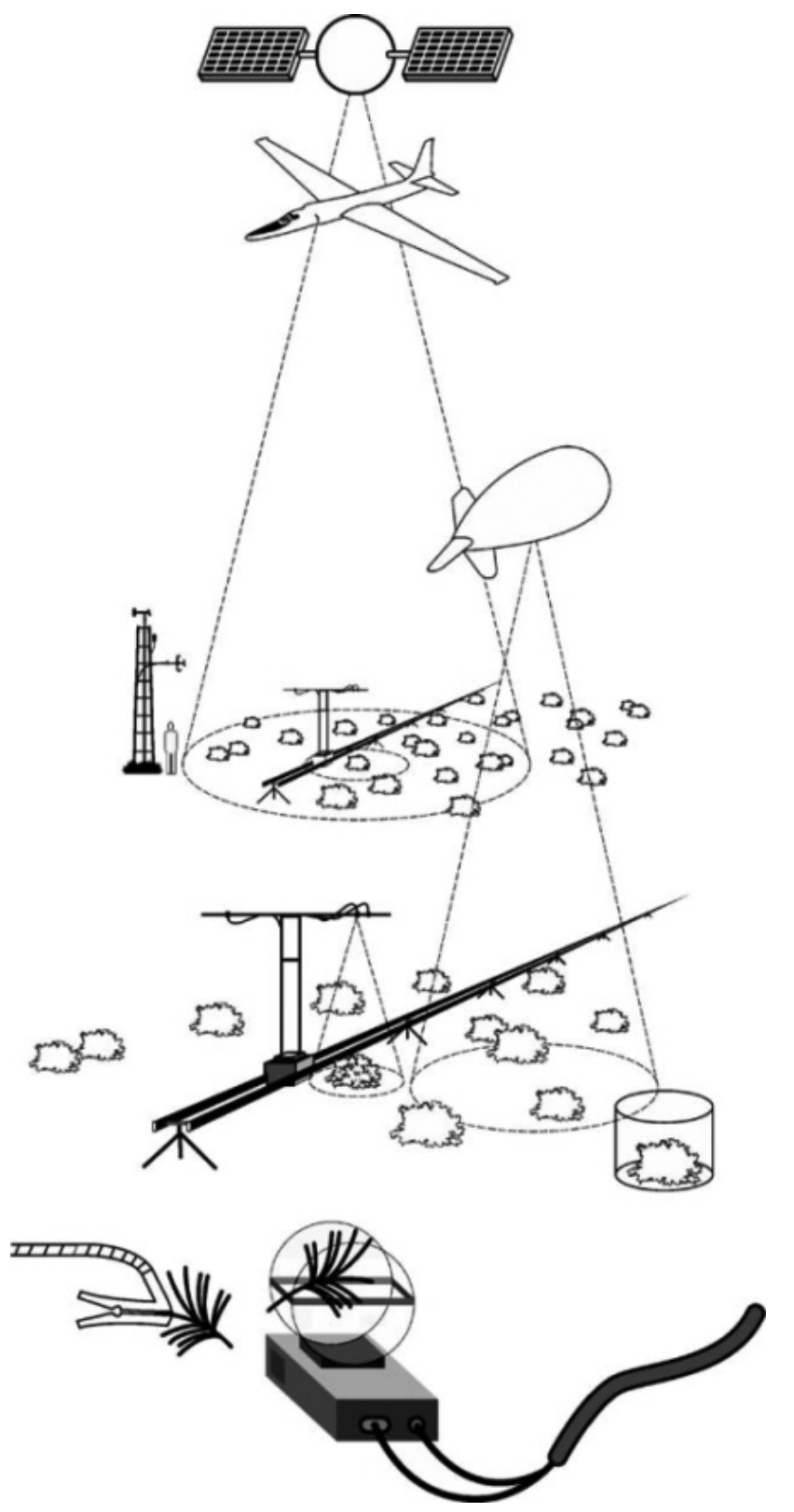

Figure 1 - Data acquisition levels (Gamon et al., 2006).

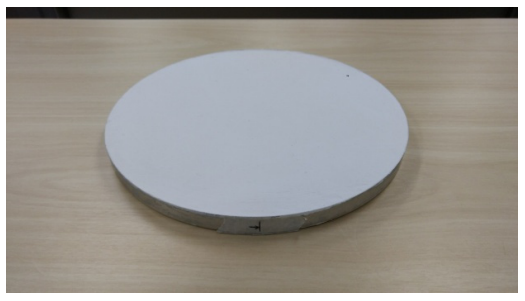

(a)

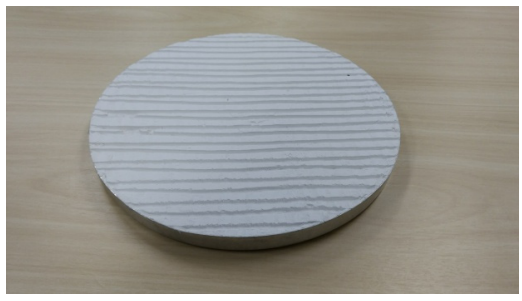

(b)

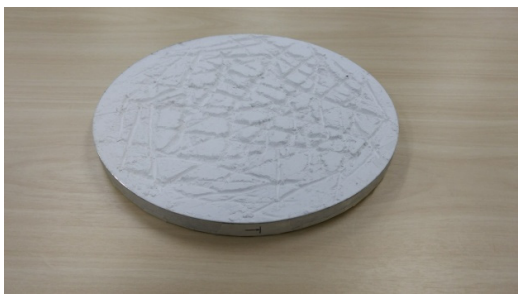

(c)

Figure 2 - Plaster surfaces used in the experiment. (a) S1, flat and silky; (b) S2, with nearly parallel grooves; (c) S3, with random grooves. 


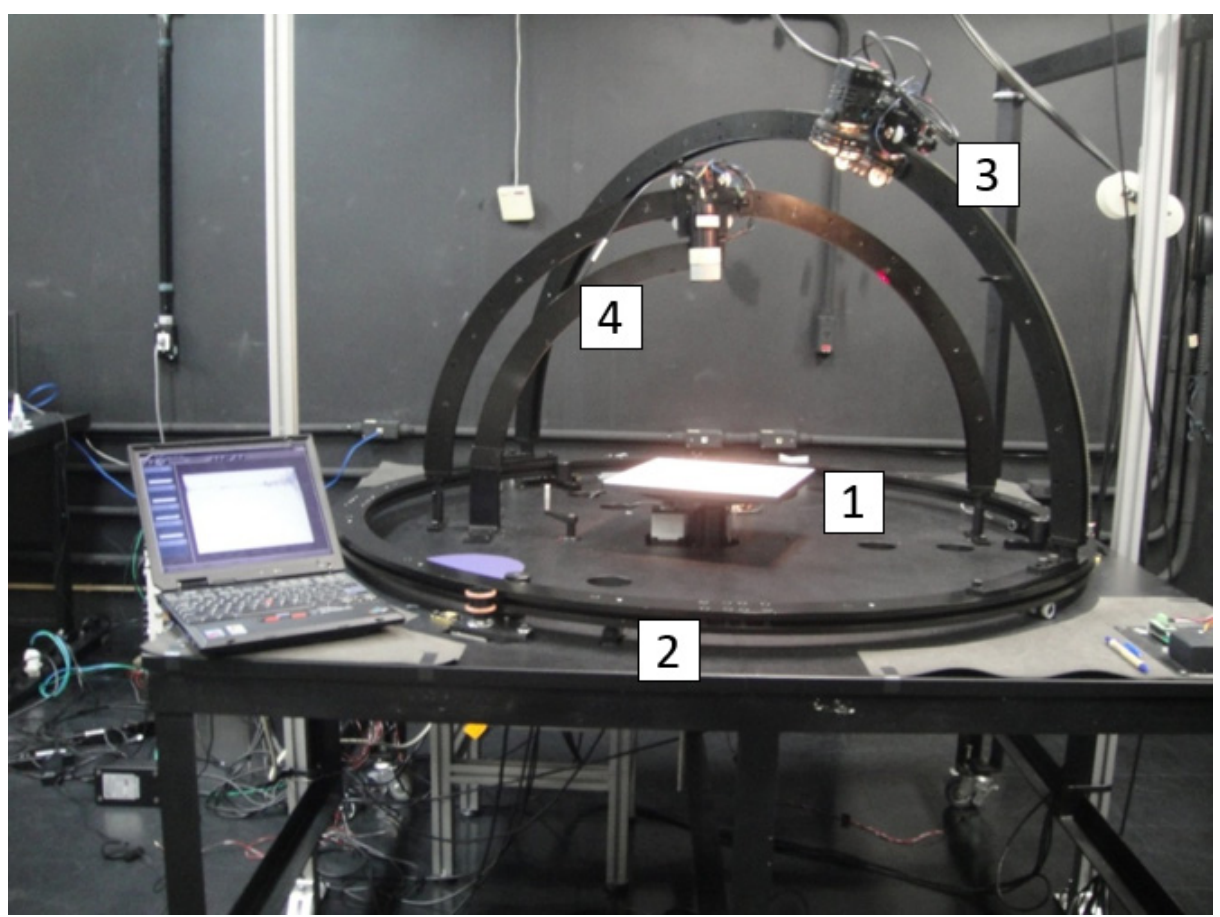

Figure 3 - Goniometer utilized during the in-lab BRDF determination. The numbers are described on the Material and Methods section.

Number 1 is the central platform in which an object can be positioned, number 2 is the main goniometer ring, number 3 is the metal arc by which the halogen lamp is supported and number 4 is the metal arc in which the ASD FieldSpec 4 radiometer optical cable is fixed. These three goniometer parts rotate permitting the BRDF characterization of an object or surface, of course, attending size constrains.

\section{BRDF Data Acquisition}

The BRDF determination of each surface was carried out in measurements cycles that started with a reference panel radiance measurement followed by automatic angular surface radiance measurements (at $15^{\circ}$ of angular interval). At the end of the cycle, new reference panel radiance was taken. This entire measurement cycle was performed three times per surface (one for each optic). A complete cycle, as shown in Figure 4, consisted of the following steps:

1. The system was calibrated in its initial position: a) source, sensor and sample holder at $0^{\circ}$ azimuth; B) sensor at $0^{\circ}$ zenith and; C) source at $15^{\circ}$ zenith. From this, the sample holder was rotated $345^{\circ}$ in azimuth, in steps of $15^{\circ}$, totaling 24 positions. A spectral radiance measurement of the surface was performed for each position. At the end of this process, the holder returned to its initial position.
2. The source was positioned at the next azimuth angle, which varied from 0 to $345^{\circ}$, in steps of $15^{\circ}$. For each new azimuth position of the source, step (1) was repeated. At the end of this process, the source returned to its initial azimuth position.

3. The source was positioned at the next zenith angle, ranging from 15 to $60^{\circ}$ in steps of $15^{\circ}$. For each new zenith position of the source, steps (1) and (2) repeated. At the end of the process, the system returned to its initial position.

For operational reasons, the complete cycle was divided into smaller cycles, called primary cycles, which consist of the combination of steps 1 and 2, totaling a time interval of approximately $6.0 \mathrm{~h}$. Thus, each primary cycle corresponded to a fixed position of the light source. At the beginning of each primary cycle, radiance from Spectralon was measured to avoid the application of a correction for the conical effect of the illumination source.

The uncertainties associated to the radiometric measurements performed here were estimated according Eq. (1).

$$
\sigma_{\text {final }}=\sqrt{\sigma_{A}^{2}+\sum\left(\sigma_{B}\right)^{2}}
$$

where: $\sigma_{\text {final }}$ is the final uncertainty; $\sigma_{A}^{2}$ and $\sum\left(\sigma_{B}\right)^{2}$ are, respectively, the Type $A$ uncertainty and the quadratic sum of every Type B uncertainties (ABNT \& INMETRO, 2003). 


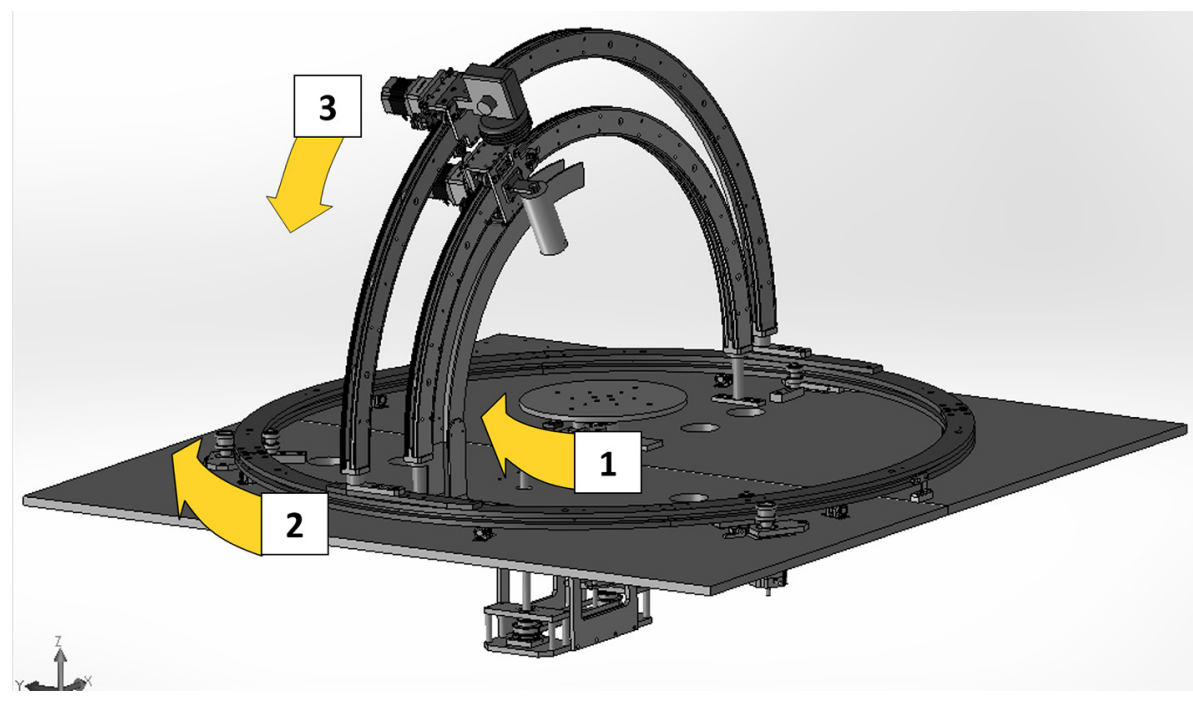

Figure 4 - Sequence of movements for the characterization of BRDF. The numbered steps are detailed on BRDF Data Acquisition section.

The evaluation Type A of the uncertainty was estimated by Eq. (2) that is based on both repeatability and reproducibility (Mendes \& Rosário, 2005).

$$
\sigma_{A}=\sqrt{\left(\sigma_{\text {repeatability }}\right)^{2}+\left(\sigma_{\text {reproducibility }}\right)^{2}}
$$

\section{Repeatability Tests}

Repeatability tests were carried out by varying the zenith angle, keeping fixed the source azimuth angle and the central platform azimuth angle, with the sensor at nadir. Thus, 30 consecutive spectral radiance measurements of a Spectralon panel was carried out, at 1.0 second intervals, for each geometry formed by the combination of the FOV and source zenith angle.

The standard deviation of the test measurements was assumed to be the repeatability uncertainty $\left(\sigma_{\text {repeatability }}\right)$. The number of repeated measurements (30) is associated with the ease of measurements and to the coverage factor from T-Student probability distribution for a correction less than $2 \%$ and therefore not required correction to obtain a confidence interval of $68 \%$.

\section{Reproducibility Tests}

The reproducibility evaluation tests were carried out per surface changing the source zenith angle from $15^{\circ}$ to $60^{\circ}$ at $15^{\circ}$ of angular intervals and maintaining constant the source azimuth angle. The ASD FieldSpec 4 optical cable and optics were maintained at nadir position. Again, at each angular interval, radiance from a reference panel (Spectralon panel) was measured to avoid the application of a correction for the conical effect of the illumination source. The complete radiometric measuring procedure was based on the following steps: a) 6 Spectralon panel measurements of spectral radiance;

b) 10 spectral radiance measurements of the plaster surface. At the beginning and the end of each one of these 10 measurements, geometry formed by the sample holder, by the support of the light source and the goniometer ring was altered and restored, in order to simulate the reproduction of the experimental apparatus. The surface has also been removed and relocated on the central platform, always in the same angular position;

c) thus, the source zenith angle was changed to the next position, in steps of $15^{\circ}$, from $15^{\circ}$ to $60^{\circ}$. At each source zenith angle, (b) and (c) were repeated.

The number of measurements (10) is related to the difficulty of operation to remove and reposition the objects. In this way, the standard deviation obtained must be multiplied by a coverage factor $\alpha=1.06$ (ABNT \& INMETR0, 2003), i.e. 6\% correction to obtain a confidence interval of $68 \%$. The standard deviation of these measurements was considered the reproducibility uncertainty ( $\left.\sigma_{\text {reproducibility }}\right)$.

With the spectral radiances, reflectance factors in band $\left(R F_{\Delta \lambda}\right)$ were obtained for the Spectralon panel, in relation to the first measurement, according to Eq. (3):

$$
\sigma_{\text {final }}=\sqrt{\sigma_{A}^{2}+\sum\left(\sigma_{B}\right)^{2}}
$$

At the end of both tests a qualitative evaluation of the samples (surfaces) reflectance factors was carried out in order to identify wavelengths in which the BRDF presented greater variations changing the instantaneous field of view (IFOV). For these 
wavelengths, data collection geometries were selected considering also the greater reflectance factor variations. Thus, the influence of IFOV on the surfaces reflectance was evaluated through Pearson Correlation Coefficients $(r)$.

\section{RESULTS AND DISCUSSION}

To facilitate the analysis of the reflectance factor behavior, data can be more conveniently visualized in three-dimensional spaces, such as the one shown in Figure 5.

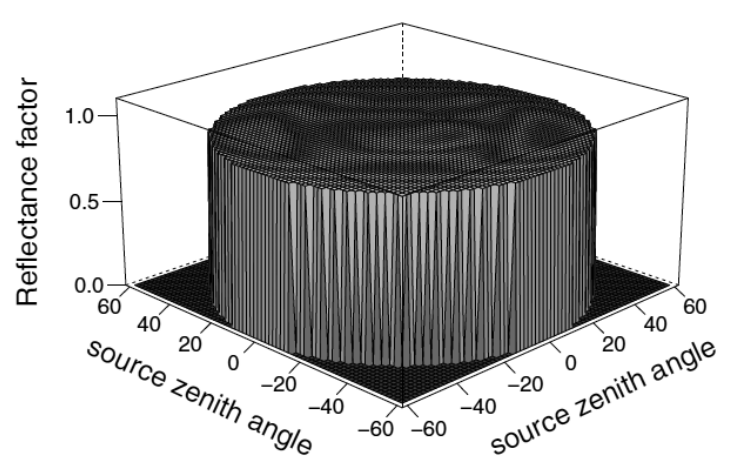

Figure $\mathbf{5}-$ RF anisotropy at $850 \mathrm{~nm}$ wavelength.

The data of Figure 5 were obtained with $1^{\circ} \mathrm{FOV}$ and refer to the wavelength of $850 \mathrm{~nm}$. The central regions of the graph of Figure 4 were linearly interpolated, because they correspond to the nadir, position in which data acquisition is not possible due to the alignment between the source and the sensor. These data were obtained from the combination of steps 1 and 3 , chosen for easily visualization of the data by avoiding shadows occurrences.

By Figure 5 it can be observed that the RF remains practically constant in function of the illumination angles, similar to a Lambertian surface behavior. This behavior remained practically identical for others FOVs, $8^{\circ}$ and $25^{\circ}$, and for other wavelengths.

However, surfaces S2 and S3 showed different behaviors. Data concerning the surface S2, for the same wavelength of $850 \mathrm{~nm}$, are shown in Figure 6. For surface S3, reflectance factor behavior at $850 \mathrm{~nm}$ can be visualized in Figure 7 .

Differently from the surface $\mathrm{S1}$, reflectance factor of the surface S2, Figure 6, presented variations due to the source angles, tending to decrease according to the zenith angle increasing, both in the forward and backward directions of the coordinate system, forming periodic wave behavior as a function of azimuth angle. Such behavior is more easily identified in the further explained graphs of Figure 8. Virtually identical behavior has been verified for the other wavelengths. This behavior can be explained by the geometric pattern of the grooves in surface S2. When the lines of the grooves are arranged perpendicular to the plane formed by the source and the sensor, more intense shadowing regions are formed at the lower points of the surface, interior of the grooves. However, when lines are arranged parallel to this same plane, both the highest and lowest points were similarly illuminated, not favoring shadow formation. This variation of brightness and shade therefore occurs periodically, resulting in the shape of the graphs of Figure 6 and Figure 8.

While the variability of the reflectance factor extends the same way for all FOVs in the case of the surfaces S1 and S2, for the surface S3, only for $8^{\circ}$ and $25^{\circ}$ FOVs the same pattern of variation of the reflectance factor was observed. For $1^{\circ} \mathrm{FOV}$, the three-dimensional graph behavior indicates an anisotropic feature of the reflectance factor, with greater amplitude variations, tending to increase with the rise of the source zenith angle in a specific direction.

To facilitate the observation of the reflectance factor behavior as a function of the illumination azimuth angle, data corresponding to step 1 of the complete cycle of measurements were selected, since this step corresponds to the variation of illumination azimuth angle. Thus, the BRDF behavior of the surfaces for a single source zenith angle can be easily observed.

The results on the wavelength of $850 \mathrm{~nm}$ for the three surfaces are shown in Figure 8. The data were obtained by varying the source azimuth angle, with the source zenith angle fixed at $30^{\circ}$.

In the case of surface $\mathrm{S} 1$, the reflectance factor values remain practically constant along the azimuth angle variation irrespective of the FOV used. For the surface S2, the periodic waveform variation of the reflectance factor, indicated the shadowing and brightness regions alternation due to the relative positioning between the direction formed by the surface relief and the plane formed by the illumination source and the sensor. It is interesting to note that the curves proximity corresponding to $8^{\circ}$ and $25^{\circ}$ FOVs. The curve corresponding to $1^{\circ} \mathrm{FOV}$, on the other hand, although being not close to the previous ones, presented the same format, but with different amplitude. The surface S3 curves (with irregular relief) referring to $8^{\circ}$ and $25^{\circ} \mathrm{FOVs}$, again show high proximity, in addition to remaining approximately constant along the azimuth angle variation, whereas the curve referring to $1^{\circ} \mathrm{FOV}$ presents significant variations.

In general, the three surfaces showed that the corresponding values of reflectance factor between $8^{\circ}$ and $25^{\circ}$ FOVs were equal, considering the measurement uncertainties.

The reflectance factor behaviors in function of FOV, can be explained by the portion of the surface structures observed on each surface, as discussed further. 


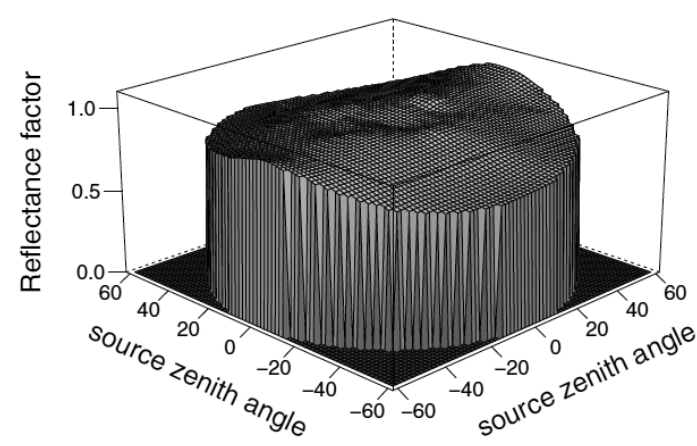

(a)

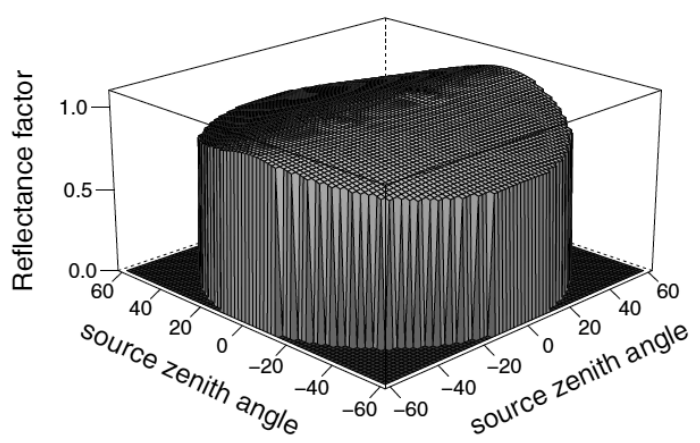

(b)

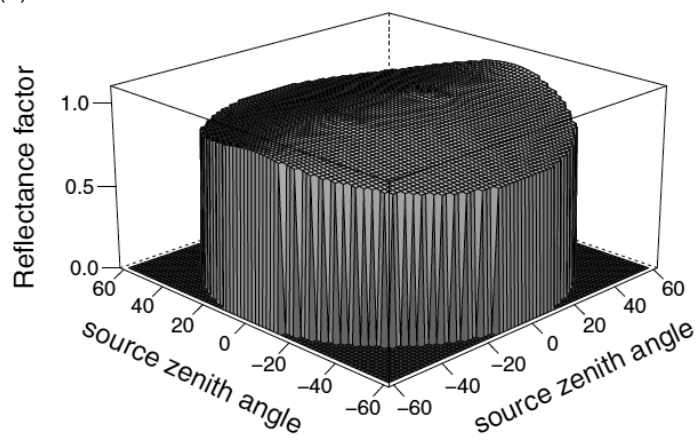

(c)

Figure 6 - Reflectance factor of the surface S2, with source ring fixed at azimuth angle $\phi=240^{\circ}$. (a) $1^{\circ}$, (b) $8^{\circ}$ and (c) $25^{\circ}$ FOV.

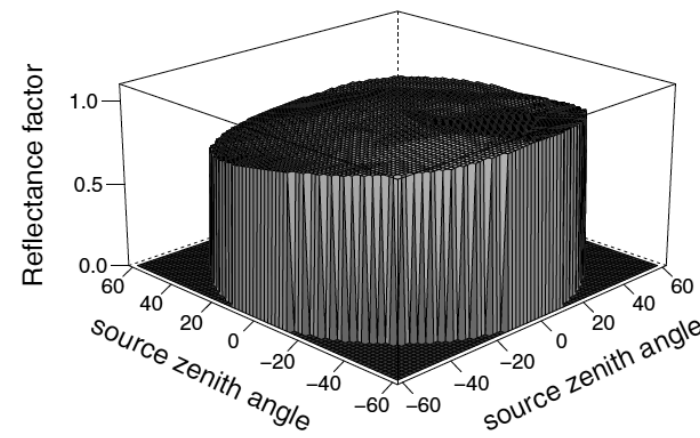

(a)

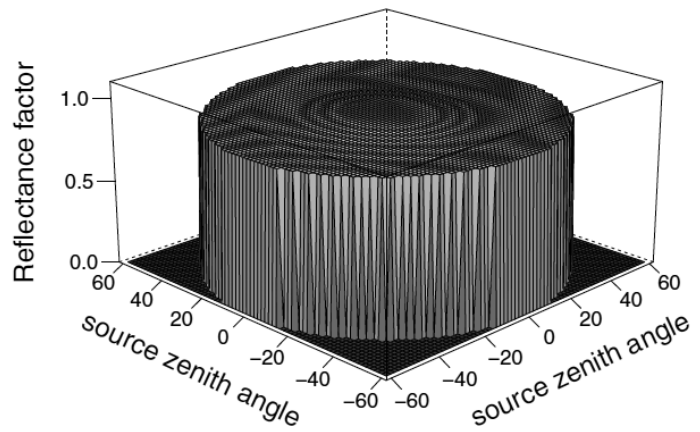

(b)

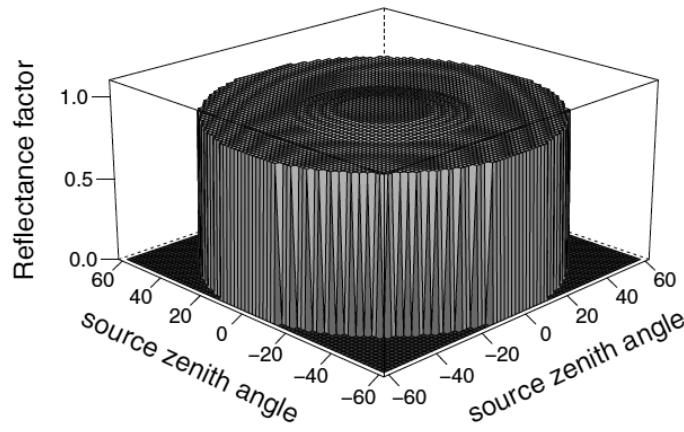

(c)

Figure 7 - Reflectance factor of the surface S3 at $850 \mathrm{~nm}$, using (a) $1^{\circ}$, (b) $8^{\circ}$ and (c) $25^{\circ} \mathrm{FOV}$. 


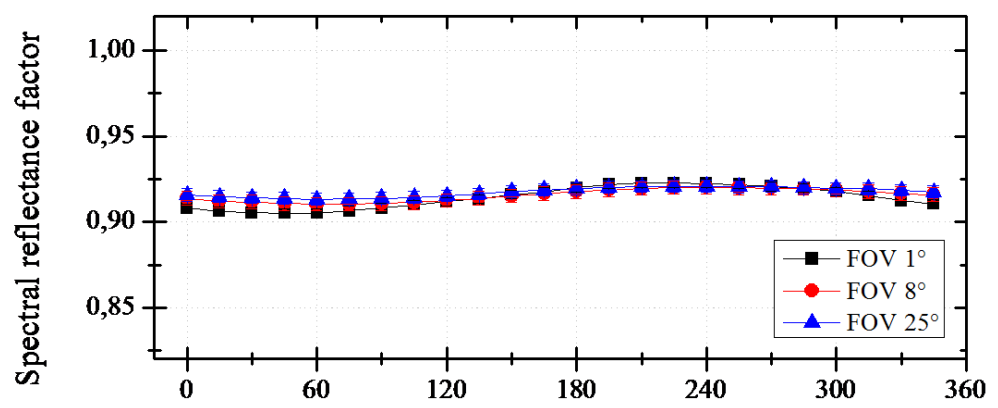

(a)

source azimuth angle

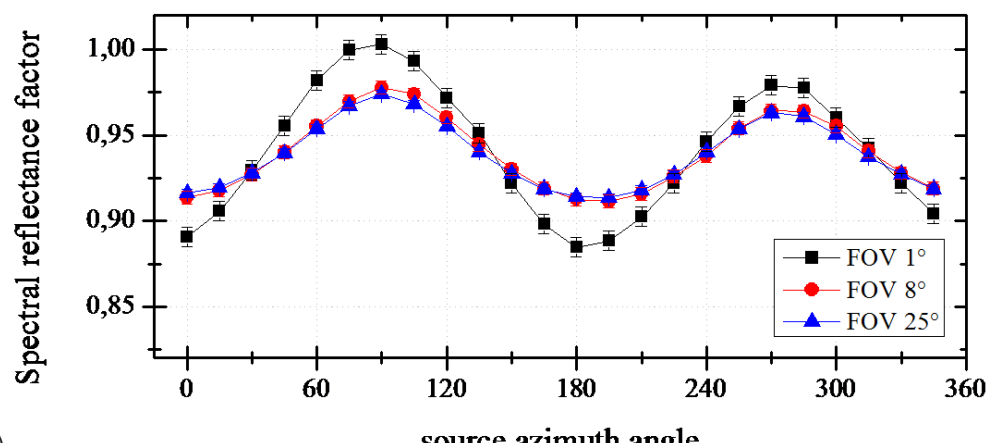

(b)

source azimuth angle

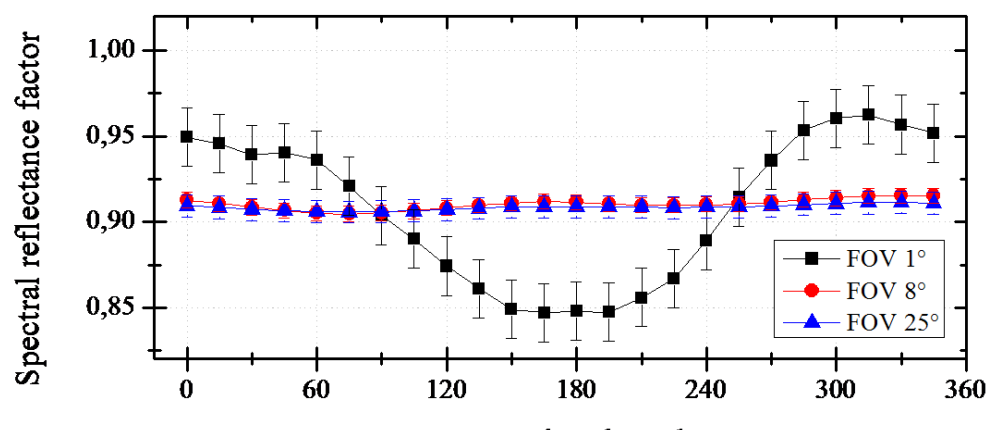

(c)

source azimuth angle

Figure 8 - Spectral reflectance factors variations according to sample support azimuth angle, for surface (a) S1, (b) S2 and (c) S3.

Considering each surface roughness, each FOV can cover, in particular, different types of superficial structures and, depending on the interaction between these structures and the incident radiation, different effects can be discriminated and then recorded by the sensor.

In the case of the flat surface, the behavior of the curves was the same for all FOVs, indicating that changing in observation scale did not influenced the surface anisotropy. Since the dimensions of surface relief (such as small holes and plaster protrusions) are in order of millimeters (about 10 times less than the order of magnitude of the lowest IFOV of $1^{\circ}$ ), the roughness observed is the same for all FOVs, i.e., the surface presents same appearance for all FOVs.
As mentioned in Material and Methods, the dimensions of the grooves in surface $\$ 2$ were approximately $1.5 \mathrm{~cm}$ spacing and $1.0 \mathrm{~cm}$ depth. Thus, $1^{\circ}$ FOV can observe in greater proportion low or high relief structures areas. As an effect, depending on the privileged object, the reflectance factor variation, i.e., the surface anisotropy of the observed area may be greater or less than the surface anisotropy as a whole. From Figure 8(b), a greater variation in the curve of $1^{\circ} \mathrm{FOV}$ than $8^{\circ}$ and $25^{\circ}$ FOVs was verified, which suggested that the FOV was projected preferentially over a low relief area, more propitious to the formation of more intense shadowing. The $8^{\circ}$ and $25^{\circ}$ FOVs covered the two types of objects practically in the same proportion, that is, on the average, high and low relief regions cover the same extent within the FOV. 
As a result, the curves relating to these FOVs resemble not only in form but also in amplitude.

For surface S3, the grooves presented no pattern of arrangement, and deformations varied from the order of fraction of centimeter to the order of units of centimeter. For this reason, the FOV projection of $1^{\circ}$ may favor one type of relief, in spite of others, so that the observed area is not representative of the entire surface. For this reason, the differentiated behavior of the $1^{\circ}$ curve in relation to $8^{\circ}$ and $25^{\circ}$ FOVs, as shown in Figure 8(c), can be justified by the fact that the FOV projection of $1^{\circ} \mathrm{FOV}$ possibly covered areas whose relief favors shadowing production in a preferred direction. On the other hand, $8^{\circ}$ and $25^{\circ}$ FOVs appear to be large enough to encompass a greater diversity of objects, so that the areas observed through these two FOVs are similar to each other as regards surface texture. Moreover, this diversity combined with the randomness of the surface relief does not prioritize the formation of shadow in a single direction. With the source zenith angle fixed and the sensor always at nadir, the azimuth variation produces regions of shadow under constant proportion, which may justify the behavior of the curves of $8^{\circ}$ and $25^{\circ} \mathrm{FOV}$.

In general, the curves of $8^{\circ}$ and $25^{\circ} \mathrm{FOV}$ remain very close, whereas the curve of $1^{\circ} \mathrm{FOV}$ resembles the others only in the case of the surface $S 1$. In the case of the surface $S 2$, the $1^{\circ}$ FoV curve maintains the same shape, varying only in amplitude, while in the case of surface S3 it differs significantly from the other curves.

\section{CONCLUSIONS}

Depending on the surface characteristics, such as roughness and topology, the spatial scaling impacts in different ways the BRDF characterization. The results indicated that, as the dimension of the sensor's FOV projection approached the size of the surface structures, BRDF began to change. Thus, we cannot assume that the BRDF propagates so invariant for all levels of data acquisition, without considering the relative dimensions between: the characteristics of the sensor system, the observed surface and distances involved in this process.

As suggestion to further works, scaling effects on the BRDF characterization can be explored in a more gradual way. For instance, it would be interesting to study the BRDF behavior when varying, by small distance steps, the distance between sensor and surface, or comparing data obtained from sensors operat- ing at different levels of acquisition, such as lab, field, airborne and orbital.

\section{ACKNOWLEDGEMENTS}

The authors would like to thank CAPES and CNPq for the financial support.

\section{REFERENCES}

ABNT - ASSOCIAÇÃO BRASILEIRA DE NORMAS TÉCNICAS \& INMETRO - INSTITUTO NACIONAL DE METROLOGIA. 2003. Guia para a expressão da incerteza de medição. 3 ed., Rio de Janeiro, Brazil: ABNT, INMETRO, $120 \mathrm{pp}$.

BILIOURIS D, VERSTRAETEN WW, DUTRÉ P, VAN AARDT JAN, MUYS B \& COPPIN P. 2007. A Compact Laboratory Spectro-Goniometer (CLabSpeG) to assess the BRDF of materials. Presentation, calibration and implementation on Fagus sy/vatica L. leaves. Sensors, 7(9): 1846-1870.

CASTRO RM, TEIXEIRA Jr JF, ANDRADE LL, RUBIATTI HT, MELO MC, MARINHO RS, LAURIA PB, BUARQUE BNMC, SILVA MM, MARQUES KCM, GARAGORRY AB, BARROS EA \& SILVA BA. 2017. Goniômetro para medições de BRDF e emissividade de materiais de interesse em SR. In: XVIII Simpósio Brasileiro de Sensoriamento Remoto, 2017, Santos. Anais do XVIII Simpósio Brasileiro de Sensoriamento Remoto. São José dos Campos: INPE, 2017. Available on: $<$ https://proceedings.galoa.com.br/sbsr/trabalhos/goniometro-paramedicoes-de-brdf-e-emissividade-de-materiais-de-interesse-em-sr> . Access on: July 10, 2017.

GAMON JA, RAHMAN AF, DUNGAN JL, SCHILDHAUER M \& HUEMMRICH KF. 2006. Spectral Network (SpecNet) - What is it and why do we need it? Remote Sensing of Environment, 103(3): 227-235.

GOODCHILD MF \& QUATTROCHI DA. 1997. Introduction: Scale, Multiscaling, Remote Sensing, and GIS. In: QUATTROCHIDA \& GOODCHILD MF (Eds.). Scale in Remote Sensing and GIS. Boca Raton: Lewis Publishers, p. 1-12.

MATHER PM \& KOCH M. 2011. Computer processing of remotelysensed images: an introduction. 4 ed., John Wiley \& Sons. 460 pp.

MENDES A \& ROSÁRIO PP. 2005. Metrologia e incerteza de medição. São Paulo, SP, Brazil: Editora EPSE, 2005. 128 pp.

PINTO CT. 2011. Avaliação das incertezas na caracterização de superfícies de referência para calibração absoluta de sensores eletroópticos. Master Dissertation (Sensoriamento Remoto), Instituto Nacional de Pesquisas Espaciais (INPE), São José dos Campos, Brazil. 135 pp. 